\title{
Emotions in the face: biology or culture? - Using idiomatic constructions as indirect evidence to inform a psychological research controversy
}

\author{
Andreas Langlotz (Basel)
}

\begin{abstract}
Research on the facial expression of emotions has become a bone of contention in psychological research. On the one hand, Ekman and his colleagues have argued for a universal set of six basic emotions that are recognized with a considerable degree of accuracy across cultures and automatically displayed in highly similar ways by people. On the other hand, more recent research in cognitive science has provided results that are supportive of a cultural-relativist position. In this paper this controversy is approached from a contrastive perspective on phraseological constructions. It focuses on how emotional displays are codified in somatic idioms in some European (English, German, French, Spanish) and East Asian (Japanese, Korean, Chinese [Cantonese]) languages. Using somatic idioms such as make big eyes or die Nase rümpfen as a pool of evidence to shed linguistic light on the psychological controversy, the paper engages with the following general research question: Is there a significant difference between European and East Asian somatic idioms or do these constructions rather speak for a universal apprehension of facial emotion displays? To answer this question, the paper compares somatic expressions that are selected from (idiom) dictionaries of the languages listed above. Moreover, native speakers of the East Asian languages were consulted to support the analysis of the respective data. All corresponding entries were analysed categorically, i. e. with regard to whether or not they encode a given facial area to denote a specific emotion. The results show arguments both for and against the universalist and the cultural-relativist positions. In general, they speak for an opportunistic encoding of facial emotion displays.
\end{abstract}

\section{$1 \quad$ Introduction}

Phraseologists have long argued that idiomatic expressions have the function of conceptualizing the world of experience of in a pre-established linguistic format. Nunberg et al. (1994: 493), for instance, call this feature "proverbiality" and claim: "Idioms are typically used to describe and implicitly, to explain - a recurrent situation of particular social interest [...]". Since idioms fixate complex conceptual micro-models in the mode of institutionalized linguistic units (Langlotz 2006: Ch. 6), idiomatic language perpetuates conventionalized and generally accepted folk views of the world (Dobrovol'skji 1995: 60). 
This paper explores the very special case of how somatic idioms encode the facial emotion displays and how they map the semantic space of emotion categories (cf. Croft 2001: 92-98; Croft and Cruse 2004: 321-323). The facial expression of emotions clearly defines "recurrent situations of particular social interest" to use Nunberg et al.'s words from the quotation above. It can thus be assumed that idiomatic constructions proverbially describe such expressions in a fixed linguistic format. More particularly, the paper adopts a contrastive perspective to scrutinize phraseological constructions from four European (English, German, French, Spanish) and three East Asian (Japanese, Chinese [Cantonese], Korean) languages to find out how they encode facial expressions of emotions.

The motivation for this comparison resides in a psychological controversy centred about the universality or cultural relativity of facial emotion displays. The universalist strand primarily developed by Ekman and his colleagues has followed Darwin's (1872) early ideas and argued that six basic or primary emotions are automatically displayed in highly similar ways and recognized with a considerable degree of accuracy across different cultures (Ekman 1973, 1992a, 1992b, 1993, 2003; Ekman and Friesen 1975, 1978; Ekman et al. 1969). Their experimental evidence speaks for the biological rooting of human facial expressions of emotions. However, the existence of universal emotion categories and innate forms of their facial display has been criticized and questioned by cultural-relativists (cf., e. g., Heelas 1996; Wierzbicka 1995). Indeed, more recent research in the area of cognitive science has provided results that speak for the cultural relativity of facial emotion displays. For example, Jack et al. (2009) have shown that East Asians focus more on the eyes, whereas Western Caucasians rather concentrate on the eyes and the mouth when orienting to and judging facial expressions of emotions. This difference seems to be reflected in Western and Eastern style emoticons as reflected in (1a) and (1b), respectively (cf. wikipedia.org: list of emoticons):

$\begin{array}{lll}\text { (1a) } & \{: 0 & =0 \\ \text { (1b) } & \text { O.o } & \text { O_o }\end{array}$

The Western style emotions — to be turned $90^{\circ}$ clockwise before reading — include the brow area, the eyes, and the gaping mouth in their abstract depiction of surprise, whereas the Eastern style emojis primarily highlight the widely opened eyes against a fairly secondary and backgrounded depiction of the mouth in terms of a period (.) and an underscore $\left(_{-}\right)$.

The depiction of the facial expression in the Western emoticons also seems to have direct linguistic correlates in the fixed expressions listed under (2):

(2) raise eyebrows, make one stare, turn up one's eyes, with gaping mouth, open-mouthed

These expressions encode the facial display of surprise by making explicit reference to the eyebrow, the eye, and the mouth areas. Somatic idioms as reflected in (2) constitute the central objects of analysis in this article. "Somatic idioms" are a subtype of phraseological constructions that contain words for body parts as lexical constituents to often encode non-verbal behaviours - including the facial expression of emotions — in a linguistic format. Somatic idioms thus describe facial emotional displays as part of the conventionalized phrasal lexicon of a specific language (Burger 2007: 94; Ziem and Staffeldt 2011: 197f.). Therefore, somatic idioms can be mobilized as a pool of indirect evidence to shed linguistic light on how different cultural communities represent the iconic facial expressions of emotion in the symbolic form 
of fixed phrasal expressions. This is interesting because such constructions may reflect which parts of the facial expressions are foregrounded through language and which ones are ignored. We can investigate how the constructions map this particular referential space and to what extent this mapping reflects universal or language-specific trends. Along the lines of this argumentation, the paper wishes to investigate whether the analysis of somatic idioms and their inter-linguistic comparison can serve to triangulate the psychological debate outlined before from the perspective of contrastive phraseology (Dobrovol'skij and Piirainen 2009: Ch. 6).

The paper addresses the following research questions:

A. How do somatic idioms encode the facial displays of different emotions, i. e. what facial areas do they cover?

B. Is there a qualitative coding difference between European (English, German, French, Spanish) and East Asian (Japanese, Korean, Cantonese) somatic idioms?

To engage with these questions, the paper is divided into seven sections. In Section 2, I will first establish the theoretical background and define the notion of emotion and address a number of theoretical and methodological problems with regard to analysing emotional expressions. Moreover, these problems are re-conceptualized in construction grammatical terms. In two subsequent sections, I will then turn to the more specific study of facial expressions of emotions and review the research debate sketched above. In Section 3 the universalist position as established by Ekman and his colleagues is first outlined and then critically appraised. The culturalrelativist counter-arguments are then presented in Section 4. Most centrally, the results of Jack et al.'s (2009) study are discussed as they provide the most important point of departure for my own empirical engagement with the controversy by means of two case studies that are offered in Sections 5 and 6. In the former I will first deal with research question A and scrutinize how facial expressions of emotions are codified in English alone. More specifically, the aim of this first case study is to find out how English somatic idioms make reference to different facial areas for different emotions. In addition, the first case study is interested in whether the facial expressions for all the basic emotions (anger, disgust, sadness, happiness, fear, surprise) that were stipulated by Ekman and his colleagues are similarly encoded in English somatic idioms or whether one can find qualitative differences in the codification of facial displays for different emotions. Section 6 will then turn to the inter-linguistic comparison in order to find out if there are qualitative differences in how these languages refer to facial areas for fear and surprise as well as anger and disgust. (The motivation for the restriction to these four emotions will become obvious later in the paper). The data for both case studies are taken from (idiom) dictionaries and thesauri. For Case Study B native speakers were consulted as informants to support the collection and analysis of the respective data. ${ }^{1}$ To close the paper, the implications of the two cases studies and potential routes for further research are addressed in the conclusion.

\section{Emotions and emotional expression - issues and epistemological problems}

Although we experience emotions introspectively on a daily basis and although we can perceive how other people communicate their own emotional states, it is extremely difficult to define

\footnotetext{
${ }^{1}$ I would like to thank Noëlle Fu and You-Jin Lee (Chinese/Cantonese), Sano Taijiro (Japanese) and Andreas Bürki (Korean) for their great help with collecting and checking somatic idioms in the respective languages.
} 
and classify these phenomena precisely because they have so far evaded the rigid grasp of science. Hence, this section cannot and does not attempt to provide an overview and discussion of alternative theories of emotion. Instead it starts from a basic definition and classification of emotion(s) to then discuss those epistemological controversies that are relevant for understanding the debate about the facial expression of emotions.

Following Damasio (1994, 1999, 2003) we can define emotions as an internal, embodied value system. They are internally represented value-categories, which can be perceived subjectively and described and expressed to interactors. However, according to Griffiths (1997), what we perceive as emotional states and what we denote by the word "emotion" may involve a fairly heterogeneous cluster of inner psychic states including related phenomena such as affect, feeling, mood, and sentiment. To account for this fuzzy nature of emotions, Plutchik $(1962,1980$, 2003) has proposed a structural model and classification of emotions by analogy with Newton's colour wheel. In doing so, he followed an earlier suggestion proposed by William James (1884):

William James was interested in the parallels between colors and emotions and stated that the naming of emotions is difficult partly because emotions merge endlessly into each other [...]. Neither colors nor emotions are clear-cut categories with sharp boundaries.

(Plutchik 2003: 103)

By adopting this colour metaphor, Plutchik's model (2003: 103-105) also concedes that emotions are not clearly delineated psychological units but that they are organized along continua of emotion types (by analogy to colour hues), similarity and polarity (by analogy to adjacent and complementary colours) and intensity (by analogy to colour saturation). Similarly to the assumption of basic or primary colours, Plutchik also proposes that there are basic emotions as, for example, fear. In terms of its intensity such a basic emotion ranges from a less intense state of apprehension, to fear, and then to intense terror. Fear stands in polarity to anger, which itself ranges from annoyance to rage. Fear, however, is adjacent to surprise with which it shares the element of facing the unexpected. The last dimension in Plutchik's structural analogy between emotions and colours constitutes the idea of blending. Like colours primary emotions may be blended to constitute secondary and tertiary emotions. For instance, a blend of fear and surprise would yield the experience of being alarmed, while a blend of fear and anger would lead to the feeling of being in conflict. Along these metaphorical lines, Plutchik's account constitutes an interesting proposal to organize and systematize the evasive nature of emotional experience. From the perspective of construction grammar, Plutchik's model is interesting because it attempts to structure the conceptual space of "emotion" to which constructions that have an emotional meaning - including the somatic idioms analysed in this paper - may refer.

In line with the basic tenets of cognitive linguistics, construction grammar has focussed on the entrenched, symbolic links between formal units of different degrees of complexity and schematicity and their semantic purport (cf., e. g., Croft 2001; Goldberg 1995, 2006). With regard to this meaning side of constructions, an encyclopaedic, multifunctional view meaning is adopted. Accordingly, constructions are seen as being coupled with complex semantic, pragmatic, and discourse-functional properties (Croft and Cruse 2004: 258). In line with this idea, one can assume that somatic idioms that encode facial expressions of emotions map a multidimensional conceptual space of emotion categories - as sketched by Plutchik - that are further related to corresponding facial actions. But do these expressions map the conceptual space in 
accord with the assumption of basic and primary emotions or do they paint the emotional picture differently?

Thus, with regard to analysing the relationship between emotions and their communication, the scarcely delineated nature of these inner psychic states leads to a further challenge. Speakers cannot directly refer to this fuzzy inner world of reference. But they can use a range of multimodal signals - a combination of verbal, vocal, facial, and bodily cues - to point to or describe it (Wilce 2009: 10). Various researchers have therefore claimed that it is necessary to draw a distinction between the description and thematization of emotional states, on the one hand, and their expression on the other (Fiehler 2002: 86-89; Foolen 2012: 350-356; Micheli 2008: 5; Schwarz-Friesel 2007: 144). A person can, for instance, express his/her anger by putting on an angry face as in (3):

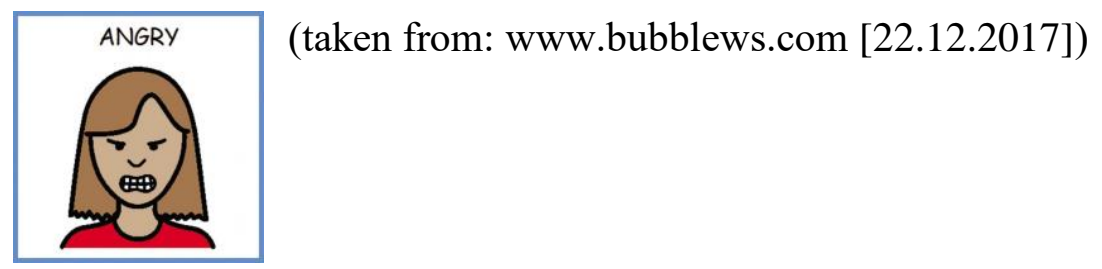

Alternatively, one can also describe or thematize emotional states and/or their expression as in

(4) She looked angrily with eyes flashing fire. This made me feel very sad.

While emotional expressions indicate the immediate emotional state of the communicator and thus appeal to the potential recipient directly, descriptions and thematizations conceptualize emotional experiences linguistically. As will be discussed below, this distinction between immediate, direct, and seemingly uncontrollable expressions versus relatively conscious descriptions and thematizations of emotional states also finds its correlates in the epistemological debate on the biological versus cultural nature of these phenomena.

Are emotions phenomena of nature, i. e. innate and biologically programmed psychic units, or must they rather be conceived as results of nurture, i. e. processes of socio-cultural construction and learning? The universalist position, which was advocated by Darwin (1872) and which was later taken up by researchers such as Ekman (1973) or Plutchik (1962) and more recently Damasio (1994, 1999), states that emotions and their expressions are fundamentally rooted in our (neuro)biological and physiological heritage as they provide us with an embodied system of automatic reactions that helps us orient to and survive in the environment. Accordingly, this universalist position sees emotions as unintentional, uncontrollable, and non-cognitive products of the body. Being internal psychic states, emotions are located at the intrapersonal level but they can be expressed through a range of verbal, vocal, facial, and bodily emotional cues. This universalist approach would speak for a highly consistent mapping of somatic idioms onto a universal conceptual space of emotion.

By contrast, the social-constructionist (Harré 1986) and cultural-relativist (cf. Harkins and Wierzbicka 2001; Pavlenko 2002) views regard emotions as products of culture(s). As the internal psychic states that we associate with emotionality are fuzzy, they are subject to cognitive processes of interpretation, which are socially and culturally shaped and therefore variable. As a result, emotion categories and concepts are not considered biologically pre-given but as the emergent linguistic and discursive products of labelling, describing, and thematizing emotional

ISSN 1615-3014 
states through language-specific emotion vocabularies and through culture-specific practices for managing emotional experiences. For instance, fear is not just seen as an automatic reaction to a threatening stimulus but as a complex discursive construct that provides socially accepted labels for fear-related feelings, that highlights what should be considered fearful through scary stories and narratives, and that offers socially-sanctioned solutions for dealing with fear. Thus, according to the social-constructionist and cultural-relativist views, emotions are seen as embedded in the social and moral order of a given society and culture rather than being grounded in the biology of the body alone.

With regard to emotional communication, the social-constructionist and cultural-relativist positions speak against automatic emotional expressions but instead argue that forms of emotional communication are bound to conventions of appropriate emotional display (Planalp 1999: Ch. 7), which have to be learnt through complex processes of emotional socialization (Hochschild 1983; Ochs and Schieffelin 1989). Moreover, they claim that communicators do not merely express their emotions but often employ emotionalized statements for strategic purposes, i. e. to influence the recipients' reactions and actions. One could therefore expect that somatic idioms in different languages map the meaning space of emotion more variably than would be hypothesized by the bio-programme theory.

The bio-programme vs. socio-cultural construction controversy finds its direct correlates in the analysis of facial expressions of emotions. Therefore, it is of fundamental relevance for the present study and the research questions A and B listed in Section 1. In line with the universalist position, we could hypothesize that people from different cultures show the same facial expressions for displaying basic and primary emotions and that the somatic idioms that circumscribe these facial displays do not reflect striking variability across cultures. In accord with the sociocultural position, we should however postulate that the linguistic descriptions of facial expressions of emotion are diverse because the members from different cultures should also be expected to vary in their expression and interpretation of emotions that are communicated through the face. This leads us to a short presentation of the universalist and cultural-relativist positions with a more precise focus on facial expressions only.

\section{The facial expression of emotions - the universalist position}

The universalist tradition of analysing facial expressions of emotion was started by Charles Darwin (1872) in his book The Expression of the Emotions in Man and Animals. He launched this research strand by focussing his research on discrete basic/primary emotions and limiting it to facial expressions. This restrained object of analysis was clearly motivated by Darwin's interest in the biological continuities between humans and animals rather than cultural variation. Therefore, he prioritized unintentional displays instead of deliberate emotional communication and he removed his analysis from everyday social contexts (cf. Planalp 1998: 30).

Darwin's research endeavour was only taken up a century later when the psychologist Paul Ekman and his colleague Wallace Friesen systematized the analysis of facial expressions of emotion by developing the Facial Action Coding System or FACS (Ekman and Friesen 1975, 1978). They claim:

We know the specific signals in each part of the face that convey the messages of fear, surprise, sadness, happiness, anger, disgust, and combinations thereof. 
(Ekman and Friesen 1975: 12)

Thus, their analytical framework starts from the assumption of six basic or primary emotions (fear, surprise, sadness, happiness, anger, disgust) and the postulate that these emotions are iconically expressed through the face by activating different facial areas. The three facial areas comprise:

(a) the brows and the forehead,

(b) the eyes and the eyelids,

(c) the lower face, including the nose, the mouth, the cheeks, and the chin.

For instance, the facial expression of anger as in (3) can be coded by accounting for its emotionspecific forms of activation in these three facial areas (cf. Ekman and Friesen 1975: 95-97). With regard to (a), the brows are lowered and drawn together, which causes vertical lines to appear between the brows. In the eye and eyelid area (b), one may observe that the lower lid is tensed and potentially raised. The upper eyelids are tense and may be lowered by the action of the brow or not. This leads to the impression of a hard stare and bulging eyes. In the lower face (c) the lips may either be pressed firmly together with the corners of the mouth going straight down or the mouth can be open and tensed into a square-like shape as if one were shouting (see (3)). With this open anger mouth communicators show their bare teeth. Note that the facial actions in the facial areas (a)-(c) also constitute the referential domain which somatic idioms for facial expressions of emotions may encode in a lexically-rich phrasal format in order to describe recurrent emotional experiences.

Beyond the prototypical displays for the six basic emotions, the facial expressions are highly flexible and adaptable in various respects. First, the facial areas can also be activated separately to vary the intensity of the expression. For instance, one can put on an annoyed or critical look by just activating the anger display in areas (a) and (b) while leaving (c) neutral. Note, however, that the expression of anger can be ambiguous unless it is displayed in all three areas (Ekman and Friesen 1975: 88). Moreover, different emotion displays can be blended to produce combinations between basic emotion displays in order to communicate more complex secondary emotions. For instance, the closed anger mouth can be combined with the disgust face to create the expression of strong contempt (Ekman and Friesen 1975: 93). At this point it is also important to highlight that Ekman and Friesen (1975: 20) concede that the spontaneous facial expression of emotions can be modulated in line with display rules. These social conventions of what emotional states we may signal in particular social contexts cause people to intensify, deintensify, simulate, inhibit, or mask emotional displays in the face. For instance, kindergarten teachers are not supposed to put on an angry face when greeting the children although they may feel angry because they were trapped in a traffic jam on their way to work. Despite admitting this socio-cultural dimension of emotion management through display rules, Ekman and Friesen nevertheless postulate that the basic emotional displays are innate and pre-wired. The display rules only apply on a surface level of conscious emotion management, whereas the spontaneous and uncontrolled facial displays of basic emotions are seen as universal.

In various studies Ekman and his colleagues tried to provide evidence for the pan-cultural nature of facial emotion displays (Ekman et al. 1969; Ekman and Friesen 1975; Ekman 1992a, 1992b, 1993, 2003). In their fundamental study from 1969 Ekman, Sorenson and Friesen con- 
ducted emotion recognition tasks with subjects from different cultures. They showed that pictures of prototypical displays of basic emotions can be accurately classified across literate and non-literate cultures (Ekman et al. 1969, also cf. Ekman and Friesen 1975: 23-28). The same was true for a culturally isolated people from the Southeast Highlands of New Guinea. They classified most emotions accurately, but only failed to distinguish between fear and surprise (Ekman and Friesen 1975: 26). (We will come back to this failure of classification below). Similar experiments were conducted by other researchers, who came up with comparable results (Eibl-Eibesfeldt 1970; Izard 1971).

With regard to the influence of display rules the researchers give a report on another experiment in which they subjected American and Japanese students to stress-inducing films. When in isolation, the Japanese and American students showed identical reactions to the stimuli. When in company, however, the students followed the specific display rules of their cultures with the Japanese masking their unpleasant feeling more than the Americans (Ekman and Friesen 1975: 23f.). Ekman's approach suggests a universal conceptual space for emotional categories and their primordial facial display.

Thus, while providing evidence for the universal nature of basic facial emotion displays, Ekman and his colleagues' studies have not remained unchallenged. The counter-arguments from the cultural-relativist camp are discussed in the next section.

\section{The facial expression of emotions - cultural-relativist counter-arguments}

Cultural-relativists and social-constructionists have attacked Ekman and his colleagues' universalist claims on both theoretical and methodological grounds. Most importantly, Ekman et al.'s (1969) methodology underlying the facial recognition tasks has been criticized along the following lines (cf. Planalp 1999: 212f.).

First, the facial recognition experiments are based on isolated photographs of good examples of prototypical facial expressions that were posed by actors. Such isolated facial expressions may be much more easy to classify than the expression of emotional states as they occur in spontaneous interaction. So accuracy levels may be unnaturally increased due to the specific experimental setup (Motley and Camden 1988).

Second, the pictures of the basic emotions are chosen according to a Western theory of emotion - a conception that regards emotions as expressible internal psychic states that are organized round a set of primary emotions. Thus, accuracy testing is culturally biased in itself because it assumes an individual, internal state model of emotion. For Russell (1994) the assumption of such distinct emotions and corresponding distinct facial expressions is taken as a premise for the recognition experiments rather than being seriously tested through empirical methods. Indeed, it has been shown that Western basic emotion words often do not translate well into other cultures (cf. also Heelas 1996). Moreover, the very task of having to classify pictures of a Western set of primary emotions may appear strange to people from cultures who have a fairly different conception of emotionality (cf. Planalp 1999: Ch. 7). So in Planalp's (1998: 31) words: "many studies force observers to choose among those same categories of emotions without regard for whether they are suitable and whether there are methodological artifacts". 
Third, Russell (1994) shows that negative and positive emotions are generally distinguished quite accurately, whereas informants have more difficulties when they have to make distinctions among the negative emotions sadness, fear, anger, and disgust. Negative emotions are more likely to be confused with one another. The same is true for blended emotions. Remember that Ekman and Friesen (1975: 26) further observed that their Papua New Guinea informants found it difficult to keep fear and surprise expressions apart. So accuracy levels are not stable across the postulated set of basic emotions. These observations tie in with Van Brakel's criticism:

what the data gathered ... may show is that people often make appropriate guesses at other people's emotions, even cross-culturally, just as they often make appropriate guesses about people's beliefs, intentions, and so on; but this is a far cry from stating [that] there's universal agreement on what, say, a prototypical sad expression is, let alone agreement on what, in general, is a sad expression.

(Van Brakel 1993, cited in Wierzbicka 1995: 35)

Fourth, Ekman and his colleagues ignored the potential impact of socio-cultural prescriptions on the facial expression of emotions. Although they acknowledge the influence of social display rules, such conventions of appropriate emotional signalling and normative interpretation have not been part of the basic research design of facial recognition experiments. However, research has amply shown that the presence vs. absence of other people influences facial expressions (e. g., Bavelas et al. 1988). People emote more when they watch a film in social situations than when they watch it alone (cf. also Ekman and Friesen 1975: 23-24). The strong impact of the social environment on the ways people signal emotions suggests that they do not merely express their feelings automatically and unintentionally but that they rather tend to communicate emotions to others in accord with socially and culturally specific norms and conventions. The traditional research on facial expressions underestimated this high degree of communicative design (Planalp 1998: 32).

To prove the cultural impact on facial recognition tasks, Jack et al. (2009) conducted eye-movement experiments with East Asian (EA) and Western Caucasian (WC) observers in their recent study "Cultural confusions show that facial expressions are not universal" (cf. also Michel et al. 2006). When judging facial expressions, the EA observers focus more intensely on the eyes, whereas the WC focus on both the eyes and the mouth. Moreover, the EA observers use a culture-specific decoding strategy that does not allow them to recognize fear and disgust accurately:

EA observers systematically biased [their eye movements] toward the eye region. A model observer revealed that EA observers sample information that is highly similar between certain expressions (i. e., "fear" and "surprise"; " disgust" and "anger")

(Jack et al. 2009: 1545)

Thus, due to their culture-specific perceptual strategy EA confuse fear with surprise and disgust with anger. Because of the lesser involvement of the mouth area in their facial perception of emotions, EA observers have a tendency to sample more ambiguous information. Jack et al. (2009: 1545), however, further show that EA biased their categorizations towards less socially threatening emotions, e. g. they favored surprise over fear. One cannot merely regard these perceptions as a "categorization error". Rather, rules of appropriate social conduct seem to influence the informants' online perceptual processes and their eye movements when recognizing 
facial expressions of emotions. Thus, it is important to note that, unlike predicted in Ekman and Friesen's view of display rules, EA observers do not discard an initially correct classification to replace it by a socially appropriate one. As Jack et al. (2009: 1545) put it in their own words: "However, our eye movement data refute 'decoding rules' hypotheses of substituting an initial correct categorization with a more socially acceptable emotion.”.

Jack et al.'s results clearly speak for the operation of culture-specific forms of recognizing and categorizing facial expressions of emotion. The culture-specific orientation works at the basic level of recognition rather than as a secondary step of applying social decoding rules. However, in the light of the previous criticism directed against facial recognition tasks, their eye-movement experiments are not void of problems either. First, the distinction between Western Caucasian and East Asian cultures is very crude. Second, like Ekman and Friesen's universalist model, the study assumes the existence of a set of distinct primary emotions. These emotion categories as such are not regarded as potentially specific to Western cultures. Moreover, the corresponding basic emotional displays are still considered innate and precise and EAs are merely seen to have a sampling bias when observing them. In other words, Jack et al. implicitly adopt an ethnocentric perspective when accounting for the East Asian data. Third, the face is still experimentally isolated and social contextual information is not considered. This is problematic because, according to Matsumoto et al. (2012), accuracy values for cross-cultural judgments of facial expressions are close to $100 \%$ when further contextual information is provided.

The central aim of this paper is to approach the controversy between the universalist and the cultural-relativist positions from the perspective of phraseology. I am interested in how somatic idioms encode the referential domain of facial expressions of emotion in their constituent structure in order to find out whether phraseological constructions can be mobilized to inform the controversy in one direction or the other. Can we use these constructions to advocate a universal conceptual space of basic emotion categories or do they rather map emotional expressions in rather culture and language-specific ways?

In the introduction to this paper, I have already mentioned the following research questions:

A. How do somatic idioms encode the facial displays of different emotions, i. e. what facial areas do they cover?

B. Is there a qualitative coding difference between European (English, German, French, Spanish) and East Asian (Japanese, Korean, Cantonese [Chinese]) somatic idioms?

By taking into account the criticism derived from the previous literature review, we are now in a position to further differentiate these questions:

A1. Concerning the match between facial areas and their linguistic circumscription: Do the lexical constituents of somatic idioms encode all the dimensions of facial expression analysed by Ekman and Friesen (literally)?

A2. Concerning the assumption of six basic/primary emotions: Are there somatic idioms for the facial expression of all basic emotions?

A3. Concerning the accuracy of recognizing/distinguishing facial displays of emotion: Is the meaning of these somatic idioms distinctive or vague between different emotions? 


\section{A4. Concerning the reflection of display rules and culture-specific conceptualizations} of emotions: Do somatic idioms reflect elements of social/cultural construction in their representation of facial expressions?

B. Concerning cultural differences in perceiving and classifying facial expressions of emotion: Is there a qualitative coding difference between European (English, German, French, Spanish) and East Asian (Japanese, Korean, Chinese [Cantonese]) somatic idioms with regard to A1 to A4?

In what follows, these research questions will be dealt with in two case studies. In the first case study on English somatic idioms representing facial expressions of emotions (Section 5), I will address A1-A4. In Section 6 I will then turn to the inter-linguistic comparison of somatic idioms in line with question $B$.

\section{Case Study A - The codification of facial expressions in English somatic idioms}

Languages are dynamic and creative symbolic systems that make it possible to their users to describe and conceptualize their worlds of experience in highly adaptable ways. Within linguistic systems, phraseological constructions are a particularly interesting resource of information with regard to the linguistic representation of world-views as they constitute conventionalized, lexically fixed and conceptually pre-patterned solutions to the challenge of representing recurring experiences (Dobrovol'skij and Piirainen 2009; Langlotz 2006). Somatic idioms are a subclass of phraseological constructions that are specialized for the representation of body-related experiences. According to Burger (2007: 94) somatic idioms are idiomatic constructions that contain lexical constituents that describe body-parts. Along similar lines Ziem and Staffeldt (2011: 198) define somatisms as "phraseologisms that contain at least one body-part terms as a constituent".

To investigate the representation of facial expressions of emotion in English somatic idioms with regard to questions A1-A4, I collected the relevant expressions from two sources: the "Roget's Thesaurus Online" and the "Collins Cobuild Dictionary of Idioms". From "Roget's Thesaurus" I extracted all the somatic idioms belonging to taxon VI. "Words relating to the sentiment and moral powers". When doing so, I included only those phraseological units that encode facial expressions of emotions. This led to the exclusion of expressions such as the ones listed in (5):

(5) make the flesh creep, turn the stomach, break one's heart

Moreover, I reduced the lexical variants of somatic idioms like (6). I treated such expressions as variants of the idiom have tears in one's eyes:

(6) draw tears from the eyes, have eyes overflowing with tears, with tears in one's eyes

The list of expressions drawn from Roget's Thesaurus was then checked against the expressions listed in the Collins Cobuild Dictionary of Idioms. Whenever necessary, expressions that were not accounted for by the thesaurus were added. However, I systematically excluded all somatic idioms for facial expressions with non-emotional meanings as the one in (7):

(7) keep one's eyes open 
My search for somatic idioms for facial displays of emotion thus resulted in 58 expressions overall. In what follows, questions A1 to A4 are dealt with one after the other.

A1. Concerning the match between facial areas and their linguistic circumscription: Do the lexical constituents of somatic idioms encode all the dimensions of facial expression analysed by Ekman and Friesen (literally)?

English somatic idioms refer to all three facial areas relevant for Ekman and Friesen's Facial Action Coding System (FACS). Examples are listed in (8a)-(8c):

(8a) Idioms referring to the brows and the forehead: show a bold front, raise eyebrows

(8b) Idioms referring to the eyes and the eyelids: with upturned eyes, not bat an eyelid

(8c) Idioms referring to the lower face, including the nose, the mouth, the cheeks and the chin: turn your nose up at something, grin from ear to ear, down in the mouth, curl one's lip, show your teeth, keep your chin up

In terms of their distribution, we can observe the following match between the facial areas and the body parts referred to by the lexical constituents of the somatic expressions:

\begin{tabular}{|l|l|l|l|}
\hline Facial area & \multicolumn{2}{|l|}{ No. of somatic idioms } \\
\hline \multirow{3}{*}{ Upper face } & forehead & 2 & 7 \\
\cline { 2 - 3 } & brows & 5 & \\
\hline \multirow{2}{*}{ Eye area } & eyelids & 1 & \multirow{2}{*}{23} \\
\cline { 2 - 3 } & eyes & 22 & \\
\hline \multirow{3}{*}{ Lower face } & nose & 2 & \multirow{3}{*}{22} \\
\cline { 2 - 3 } & mouth (laugh, grin) & 13 & \\
\cline { 2 - 3 } & lips & 2 & \\
\cline { 2 - 3 } & teeth & 3 & \multirow{2}{*}{6} \\
\cline { 2 - 3 } & chin/jaw & 2 & 6 \\
\hline \multirow{2}{*}{ Overall impression } & face & 6 & \\
\hline
\end{tabular}

Table 1: Facial areas referred to by lexical constituents of English somatic idioms for facial expressions of emotion

As Table 1 reveals, the eye area (23 expressions) and the lower face area (22 expressions) are almost equally covered by the English idioms. This is congruent with Jack et al.'s result that Western Caucasians pay attention to both the eyes and the mouth when categorizing facial displays of emotion. With regard to the number of idioms referring to specific parts of the face, we notice, however, that the eyes are encoded by the greatest number of idioms (22), followed by the mouth - including actions performed with the mouth like laughing or grinning (13). The other parts of the face are referred to by fewer expressions. For instance, in the upper face area, the brows are encoded by 5 idioms. Note that 6 somatic idioms do not have specific facial parts as lexical constituents but refer to the face as a whole, e. g. to make a long face. 
In construction grammatical terms, we can thus state that the formal side of English somatic idioms is correlated with the facial "grammar" of emotional expression. But how do these formal units map onto the conceptual space of emotional meaning?

A2. Concerning the assumption of six basic/primary emotions: Are there somatic idioms for the facial expression of all basic emotions?

With regard to the match between the facial actions performed in the three facial areas and their encoding with the six specific basic emotions, the following observations can be made. For some emotions, such as surprise and disgust, the match between the descriptions provided by the idioms and the corresponding facial actions is decently close. To illustrate this, Ekman and Friesen's (1975: 45) description of surprise can be linked to corresponding somatic idioms as represented in Table 2.

\begin{tabular}{|l|l|l|}
\hline Area & Features & Somatic idioms \\
\hline $\begin{array}{l}\text { Brows and fo- } \\
\text { rehead }\end{array}$ & $\begin{array}{l}\text { - Brows raised, curved, and high } \\
\text { Horizontal wrinkles across the } \\
\text { forehead }\end{array}$ & raise eyebrows \\
\hline $\begin{array}{l}\text { Eyes and } \\
\text { eyelids }\end{array}$ & $\begin{array}{l}\text { - Eyelids opened } \\
\text { Upper lid raised } \\
\text { White of the eyes shows above } \\
\text { (and often below) the iris. }\end{array}$ & $\begin{array}{l}\text { make one stare } \\
\text { look askance at somebody/something } \\
\text { turn up one's eyes, with upturned eyes }\end{array}$ \\
\hline $\begin{array}{l}\text { Lower face } \\
\text { Jaws drop open. }\end{array}$ & $\begin{array}{l}\text { Lips and teeth are parted. } \\
\text { No tension or stretching in the } \\
\text { mouth }\end{array}$ & $\begin{array}{l}\text { your jaw drops } \\
\text { youth }\end{array}$ \\
\hline
\end{tabular}

Table 2: Facial actions for surprise and corresponding idiomatic expressions in English

However, when considering other emotions such as fear, one observes a striking absence of particular somatic idioms capturing the facial expression of fear alone. (For the overlap of surprise and fear idioms see the discussion below). Of course, there are a great many idioms denoting fear as evidenced by (9):

(9) Fear idioms: freeze one's blood; make one's flesh creep; make one's hair stand on end; make one's teeth chatter; be white as a sheet; be as pale as a ghost

These idioms describe bodily symptoms of fear but they do not represent facial fear displays. With regard to the fear-related facial expressions, English only features somatic idioms that circumscribe the inhibition of fearful facial displays (see 10) in accord with the display rule: 'show no fear'.

(10) show/present a bold front; not bat an eye/eyelid/eyelash; keep a stiff upper lip; keep a straight face

In other words, there is a gap in the mapping relationship between English somatic idioms and the assumed set of basic emotions. More specifically, these constructions seem to reflect a fearexpression bias. This is interesting because for its linguistic encoding of facial emotion displays English seems to shun away from this negatively evaluated and seemingly tabooed emotion (cf. Planalp 1999: 224). 
A3. Concerning the accuracy of recognizing/distinguishing facial displays of emotion: Is the meaning of these somatic idioms distinctive or vague between different emotions?

Interestingly, several somatic idioms that denote surprise can also be used to denote the fearrelated state of being alarmed, i. e. a blend between surprise and fear. This semantic vagueness occurs with the phraseological constructions listed under (11):

(11) make one stare; with wide-open eyes

In actual language use, the emotional meaning of these idioms must be disambiguated between surprise and fear. This can be illustrated by examples (12a) and (12b), which are taken from the British National Corpus (BNC).

(12a) "I'm in love!" he explains. Felicity gazes at him, her eyes wide open. [...]. Felicity goes on staring at him in astonishment. Then she takes his hand. (BNC GOF: 978-987)

(12b) Gaunt, head shaven, eyes wide open in horror, Miller soon realises [...]. (BNC CEK: 7034)

While the co-text of (12a) indicates that Felicity is in a state of surprise or astonishment, the prepositional phrase in horror in (12b) clearly points to a state of fear. Thus, the meaning of the somatic idiom eyes wide open is vague between these two basic emotions without being placed in a concrete context of use. This construction maps onto two basic emotions in the assumed conceptual space of primary emotions. With regard to the emotion recognition experiments reported above, this linguistic insight is very interesting as it points to the fact that the facial action in the eye area that is represented in the phraseological units does not suffice to clearly categorize the given basic emotions. On the one hand, this corroborates Jack et al.'s results claiming that a strong focus on the eye region does not allow observers to clearly distinguish expressions of surprise and fear. Moreover, and more interestingly, the sense of eyes wide open also shows that the phrasal lexicon of English does not reflect an "attempt" to clearly delineate the semantics of the somatic idioms for the facial expression of all the basic emotions that are assumed in the universalist framework. Rather, the phrasal lexicon of English seems to align with the East Asian orientation to surprise and fear. As we have seen in the previous section, surprise and fear are often "confused" in facial recognition tasks by East Asian informants. Thus, eyes wide open seems to be more "Asian" in its semantic vagueness, i. e. its non-distinct way of mapping the conceptual space of emotion categories, than would be expected from the cultural differences in the eye-movement experiments conducted by Jack et al.

A similar semantic overlap occurs with the expressions to shoot somebody a black/dirty/filthy look and look with an evil eye. These idioms are vague between disgust - more specifically its social derivate contempt - and anger. Again, as reflected in (13a) and (13b), we need contextual information to specify the context-specific emotion expressed by these facial actions:

(13a) Jessamy shot him a black look. "Are you saying it's your fault that I've got to leave my home and go into hiding?" Then her brows drew together. (BNC H8F: 502)

(13b) "He looked back at us with a proud, black look. "Name your price," he said. (BNC GV7: 41) 
In (13a) the description of the black look in combination with the clause her brows drew together points to Jessamy's angry feelings, whereas in (13b) black look is collocated with the adjective proud, which points to the social meaning of contempt. Again, this result is very interesting because it is congruent with the East Asian perceptual tendency of 'confusing' facial expressions of disgust and anger in facial recognition tasks. English also reflects this vagueness in the semantics of some corresponding somatic idioms.

In summary, we can observe that the semantics of English somatic idioms does not neatly distinguish the six basic or primary emotions. The subpart of the phrasal lexicon comprising somatic idioms that circumscribe facial displays of emotion are semantically vague between surprise and fear as well as disgust/contempt and anger. This is primarily true for those idioms that refer to the eye region. For fear alone English does not have any somatic idioms capturing facial actions that unambiguously point to this emotion. The meanings of the somatic idioms for the other basic emotions - sadness, happiness, anger - are more neatly distinguishable. However, for an expression like with tears in one's eyes it is not clear again whether it is caused by a state of happiness or sadness. In other words, the semantic space for English somatic idioms does not support the general idea of a nicely delineated set of basic emotions with unambiguously matching idiomatic phrases. The linguistic data points to a more opportunistic approach to mapping emotional meanings by means of fixed phrases. This observation is in line with those approaches that claim that facial signals are often interpreted in conjunction with other emotional signals and contextual information rather than being digested in isolation (Matsumoto et al. 2012; Planalp 1998: 32, 1999: 214; Russell 1994).

A4. Concerning the reflection of display rules and culture-specific conceptualizations of emotions: Do somatic idioms reflect elements of social/cultural construction in their representation of facial expressions?

Above in (10), we have already seen how English idioms denoting courage incorporate the display rule of not showing fear in the face. This encoding of socio-cultural conventions of appropriate emotional display constitutes one aspect of how somatic idioms may reflect elements of the social and cultural management of facial displays of emotion. Such cultural orientations towards emotional displays also become salient in somatic idioms that contain non-descriptive, figurative components as reflected in (14).

(14) look daggers at someone; give a black look/look black as thunder; with eyes flashing fire

The metaphorical and comparative lexemes highlighted in (14) blend the literal description of facial expressions with figurative conceptualizations to provide stronger images of emotional excitation and forceful expression (Dobrovol'skij and Piirainen 2009: 39; Langlotz 2006: 7071). With regard to our research questions such blended somatic idioms are interesting as they show that language users do not draw a clear dividing line between literal descriptions of spontaneous emotional expressions and culture-specific understandings of these actions in terms of violence (daggers), natural forces (thunder, fire), colour symbolism (black). In line with the idea that constructions are mapped onto a multi-dimensional conceptual space, we can observe that this conceptual space may be heterogeneous between descriptive and metaphorical conceptualizations. 
As has been shown in the cognitive-linguistic tradition of conceptual metaphor analysis (cf., e. g., Lakoff 1987), such metaphorical conceptualizations of emotions are regular and systematic. Moreover, cognitive linguists have shown that highly similar conceptual metaphors are employed in different cultures to conceptualize emotions (Kövecses 2002). This, however, does not contradict my observation that several somatic idioms are opportunistic between describing facial displays of emotions in conjunction with conceptualizing these displays in figurative terms.

To summarize our insights from this first case study on English somatic idioms, we have seen that with regard to making reference to the different facial areas English somatic idioms match Ekman and Friesen's FACS well. For some emotions, such as surprise, the congruence between the set of somatic idioms and Ekman and Friesen's descriptors is high. This speaks for the adequacy of their arguments. Counter-evidence, however, comes from fear-related idioms, which do not make reference to facial actions. Fear-related facial-action idioms can only be found in overlap with the set of surprise idioms. Such overlap also occurs with the emotions anger and disgust/contempt. Somatic idioms that point to the eye region are vague between these two emotional states. Thus, the system of English somatic idioms for facial expressions of emotion does not unambiguously map onto the six basic emotions assumed in the universalist theory. Finally, elements of social and cultural construction can be found with phraseological constructions that encode display rules (courage as the avoidance of fear expressions) or convey blended images of facial actions with figurative conceptualizations. In what follows, these insights are further scrutinized inter-linguistically.

\section{Case Study B - Evidence from other European and East Asian languages on fear/surprise and anger/disgust}

In this section, the main insights from Case Study A are further examined in an inter-linguistic comparison. As the separation between fear and surprise as well as anger and disgust proved to yield the most interesting insights with regard to the controversy between universalists and relativists, this second case study concentrates on these basic emotions only. It scrutinizes the following research question:

B. Concerning cultural differences in perceiving and classifying facial expressions of emotion: Is there a qualitative coding difference between European (English, German, French, Spanish) and East Asian (Japanese, Korean, Chinese [Cantonese]) somatic idioms with regard to A1 to A4?

The collection of relevant somatic idioms was based on dictionaries and thesauri and supplemented by information given by native speakers (see Section 1).

In line with Jack et al.'s distinction between Western Caucasian and East Asian informants, this short analysis is based on four European (English, German, French, Spanish) and three East Asian (Japanese, Chinese/Cantonese, Korean) languages. Note that the choice of these languages is not systematic but based on convenience, i. e. on my own linguistic knowledge as well as the possibility of recruiting informants for the East Asian languages. In order to gain a richer picture, it would of course be necessary to include several other languages. Also note that in line with Case Study A, I do not make any claims on the frequency of use of the somatic idioms in these different languages. For my comparison I am merely interested in categorical 
distinctions, i. e. in whether or not the different languages contain somatic idioms that refer to the relevant facial areas depending on the emotion that they denote.

To illustrate some of the most notable parallels and differences between the 7 languages, I will first engage in an exemplary comparison between German and Korean somatic idioms for surprise/fear and anger/disgust. The more general comparison with the other languages will then be provided in a second step.

Table 3 lists the German and Korean somatic idioms related to fear and surprise. As one can observe, both languages contain phraseological constructions representing the facial expressions for these emotions.

\begin{tabular}{|l|l|l|l|}
\hline Emotion & German & Korean & Paraphrase \\
\hline Fear & die Augen weit aufreissen & 눈이 휘둥그레지다 & eyes wide open \\
\hline \multirow{5}{*}{ Surprise } & grosse Augen machen & 눈이 휘둥그레지다 & eyes wide open \\
\cline { 2 - 4 } & $\begin{array}{l}\text { jmdm. fallen (fast) die Augen aus } \\
\text { dem Kopf }\end{array}$ & 눈알이 나오다 & eyeballs come out \\
\cline { 2 - 4 } & die Augenbrauen hochziehen & & \\
\cline { 2 - 4 } & mit offenem Mund dastehen & 입이 떡 벌어지다 & mouth wide open \\
\cline { 2 - 4 } & jmdm. fällt die Kinnlade runter & & \\
\hline
\end{tabular}

Table 3: German and Korean somatic idioms for facial displays of fear and surprise

The following points seem particularly notable with regard to the data.

First, the overlap between open-eyed fear and surprise expressions that was already evidenced for English can also be detected in the German and Korean phrasal lexicon. While German makes a subtle distinction between the more fear-based action of widely opening one's eyes rapidly (die Augen weit aufreissen) and the more static image of making very big 'surprise eyes' (grosse Augen machen), Korean has the same idiom눈 이 휘둥그레지다 (eyes wide open) for both fear and surprise. Again this is congruent with our previous observation that eye-related somatic idioms for fear and surprise are semantically vague between the two emotions. The semantic mapping of German and Korean idioms is similar in that respect.

Second, it is very interesting that Korean encodes the open mouth for surprise. This runs counter to Jack et al.'s (2009) observation that the mouth region tends to be avoided by East Asians when perceiving facial displays of emotion. Maybe the mouth region is encoded for this emotion because surprise is seen as a positive rather than a socially-threatening emotion. What is also noticeable is that Korean does not make explicit reference to the eyebrows and the chin when representing surprise expressions. This insight should not be over-interpreted, however, because it may just reflect different preferences for describing the upper and the lower face areas in the two languages. 
The German and Korean somatic idioms for anger and contempt are listed in Table 4.

\begin{tabular}{|c|c|c|c|}
\hline Emotion & German & Korean & Paraphrase \\
\hline \multirow[t]{6}{*}{ Anger } & die Stirn runzeln & & \\
\hline & $\begin{array}{l}\text { mit zusammengezogenen } \\
\text { Augenbrauen }\end{array}$ & & \\
\hline & \multirow{3}{*}{$\begin{array}{l}\text { mit stechenden Augen } \\
\text { mit stechendem Blick }\end{array}$} & 눈알이 곤두서다 & eyeballs stand out \\
\hline & & 눈에 쌍심지를 켜다 & $\begin{array}{l}\text { a candlewick ignites in } \\
\text { the eyes }\end{array}$ \\
\hline & & 눈에 천불이 나다 & fire comes out of the eyes \\
\hline & Zähne zeigen & & \\
\hline \multirow{6}{*}{$\begin{array}{l}\text { Contempt/ } \\
\text { Disgust }\end{array}$} & die Stirn runzeln & \multirow[t]{2}{*}{ 미간을 찌푸리다 } & \multirow[t]{2}{*}{ to frown between the eyes } \\
\hline & $\begin{array}{l}\text { mit zusammengezogenen } \\
\text { Augenbrauen }\end{array}$ & & \\
\hline & $\begin{array}{l}\text { die Augen verdrehen/rol- } \\
\text { len }\end{array}$ & & \\
\hline & die Nase rümpfen & & \\
\hline & eine Schnute ziehen & 똥씹은 표정 & $\begin{array}{l}\text { make a face as if one had } \\
\text { to eat excrements }\end{array}$ \\
\hline & $\begin{array}{l}\text { einen schiefen Mund ma- } \\
\text { chen }\end{array}$ & 입을 씰룩거리다 & the mouth shakes \\
\hline
\end{tabular}

Table 4: German and Korean somatic idioms for facial displays of anger and disgust/contempt

Again, one can perceive that Korean expressions do not make explicit reference to the forehead and the eyebrows when describing facial displays of emotion. However, similar to German, they encode the aggressive gaze for anger. This focus on the eyes is in line with Jack et al.'s eye-movement results. These results are further corroborated by the fact that Korean idioms do not indicate the mouth region for anger displays, which supports the claim that East Asians have a bias for avoiding socially-threatening emotions. Contrary to Jack et al.'s results, however, Koreans do include the lower face when representing disgust and contempt. So, again, the perceptual avoidance of the lower face area by East Asian informants is not generally supported by the phrasal lexicon of Korean. Interestingly, they do not explicitly mention the nose in the context of disgust/contempt. The appearance of the nose, however, seems to be included in the more holistic 'make a face as if one had to eat excrements' (똥씹 은 표정).

A further notable insight given by Table 4 is the presence of figurative blends for both German and Korean anger idioms. While German describes a "stinging" gaze, Korean points to the firelike character of the angry eyes. Thus, both languages blend literal descriptions of the facial expression of anger with metaphorical conceptualizations of this aggressive emotion. Again, both languages seem to make reference to a multi-dimensional space of emotional meaning.

In what follows, I will extend this exemplary comparison between German and Korean to a more integrative juxtaposition of all languages analysed.

The first basic emotion to be analysed is fear. The comparative results are represented in Table 5 . 


\begin{tabular}{|c|c|c|c|c|c|c|c|c|c|}
\hline Emotion & $\begin{array}{l}\text { Facial } \\
\text { area }\end{array}$ & Body part & Eng & Ger & Fr & Sp & Jpn & Kor & Chn \\
\hline \multirow[t]{6}{*}{ Fear } & \multirow{2}{*}{$\begin{array}{l}\text { Upper } \\
\text { face }\end{array}$} & Forehead & & & & & & & \\
\hline & & Brows & & & & & & & \\
\hline & Eye area & Eyes/eyelids & $\mathrm{x}$ & $\mathrm{x}$ & $\mathrm{x}$ & $\mathrm{x}$ & $\mathrm{x}$ & $\mathrm{x}$ & $\mathrm{x}$ \\
\hline & \multirow{3}{*}{$\begin{array}{l}\text { Lower } \\
\text { face }\end{array}$} & Nose & & & & & & & \\
\hline & & Mouth (lips, teeth) & & & & & & & \\
\hline & & Chin & & & & & & & \\
\hline
\end{tabular}

Table 5: Facial areas covered by somatic idioms reflecting facial displays of fear in 7 languages. The areas with a $x$ mark whether somatic idioms in the respective languages encode these facial areas (the same applies to tables 6-8).

What is striking about the encoding of the different facial areas with this emotion is that it overlaps with surprise expressions in all languages. In other words, the languages are vague between facial expressions of fear and surprise as they make reference to the widely open eye area for both basic emotions. This pattern should neither be expected in Ekman and Friesen's universalist nor in Jack et al.'s cultural-relativist framework. The latter model would predict a more striking difference between Western and East Asian orientations to the facial displays of these emotions, whereas the former would predict that somatic idioms would encode specific facial displays of the primary emotion of fear. Instead all languages seem to ignore the distinctiveness between fear and surprise in their sets of somatic idioms that encode facial actions for these emotions. Instead of increasing the distinctiveness between open-eyed fear and open-eyed surprise, they conflate these two emotions in the semantics of the corresponding somatic idioms.

With regard to surprise the following pattern emerges (see Table 6).

\begin{tabular}{|c|c|c|c|c|c|c|c|c|c|}
\hline Emotion & $\begin{array}{l}\text { Facial } \\
\text { area }\end{array}$ & Body part & Eng & Ger & Fr & Sp & Jpn & Kor & Chn \\
\hline \multirow[t]{6}{*}{ Surprise } & \multirow{2}{*}{$\begin{array}{l}\text { Upper } \\
\text { face }\end{array}$} & Forehead & & & & & & & \\
\hline & & Brows & $\mathrm{x}$ & $\mathrm{x}$ & $\mathrm{x}$ & $\mathrm{x}$ & & & $\mathrm{x}$ \\
\hline & Eye area & Eyes/eyelids & $\mathrm{x}$ & $\mathrm{x}$ & $\mathrm{x}$ & $\mathrm{x}$ & $\mathrm{x}$ & $\mathrm{x}$ & $\mathrm{x}$ \\
\hline & \multirow{3}{*}{$\begin{array}{l}\text { Lower } \\
\text { face }\end{array}$} & Nose & & & & & & & \\
\hline & & Mouth (lips, teeth) & $\mathrm{x}$ & $\mathrm{x}$ & $\mathrm{x}$ & $\mathrm{x}$ & $\mathrm{x}$ & $\mathrm{x}$ & $\mathrm{x}$ \\
\hline & & Chin & $\mathrm{x}$ & $\mathrm{x}$ & & & & & \\
\hline
\end{tabular}

Table 6: Facial areas covered by somatic idioms reflecting facial displays of surprise in 7 languages

The somatic idioms in all languages encode the eye area and the lower face area to represent the corresponding facial expression. Slight differences occur with the lexical coding of the brows, which is present in all European languages as well as Cantonese, and the explicit reference to the chin, which is only attested for English and German. The picture for these idioms speaks for Ekman and Friesen's universalist claims, whereas it contradicts the perceptual tendencies reported by Jack et al.

Anger-related somatic idioms that represent facial displays orient to the different facial areas in the following ways (Table 7): 


\begin{tabular}{|c|c|c|c|c|c|c|c|c|c|}
\hline Emotion & $\begin{array}{l}\text { Facial } \\
\text { area }\end{array}$ & Body part & Eng & Ger & Fr & Sp & Jpn & Kor & Chn \\
\hline \multirow[t]{6}{*}{ Anger } & \multirow{2}{*}{$\begin{array}{l}\text { Upper } \\
\text { face }\end{array}$} & Forehead & & $\mathrm{x}$ & $\mathrm{x}$ & $\mathrm{x}$ & & & \\
\hline & & Brows & $\mathrm{x}$ & $\mathrm{x}$ & $\mathrm{x}$ & $\mathrm{x}$ & $\mathrm{x}$ & & \\
\hline & Eye area & Eyes/eyelids & $\mathrm{x}$ & $\mathrm{x}$ & $\mathrm{x}$ & $\mathrm{x}$ & $\mathrm{x}$ & $\mathrm{x}$ & $\mathrm{x}$ \\
\hline & \multirow{3}{*}{$\begin{array}{l}\text { Lower } \\
\text { face }\end{array}$} & Nose & & & & & & & \\
\hline & & Mouth (lips, teeth) & $\mathrm{x}$ & $\mathrm{x}$ & $\mathrm{x}$ & $\mathrm{x}$ & & & $\mathrm{x}$ \\
\hline & & Chin & & & & & & & \\
\hline
\end{tabular}

Table 7: Facial areas covered by somatic idioms reflecting facial displays of anger in 7 languages

All four European languages cover all three facial areas consistently. English does not have a somatic idiom for frowning the forehead in anger, but this detail is not of high relevance. More interestingly, it is for this emotion that we see the most striking discrepancy between the Western and the East Asian languages. While the former highlight the anger mouth, Japanese and Korean do not encode the angry display of the bare teeth. This gap in the table is also congruent with Jack et al.'s results and it may be in line with the culture-specific display rules for anger expressions in these languages/cultures. However, Chinese departs from this East Asian trend. According to my informants 'gnashing one's teeth in anger' is a conventional Chinese expression for its facial display. The absence of explicit reference to the brow in Korean and Chinese as well as the forehead in all three languages is striking too, but it cannot be explained within the theoretical and analytical scope of this paper.

Finally, Table 8 shows the match between somatic idioms and the encoded facial areas for contempt/disgust. As one can see, the picture for this emotion is fairly heterogeneous.

\begin{tabular}{|l|l|l|c|c|c|c|c|c|c|}
\hline Emotion & Facial area & Body part & Eng & Ger & Fr & Sp & Jpn & Kor & Chn \\
\hline \multirow{3}{*}{$\begin{array}{l}\text { Contempt } \\
\text { Disgust }\end{array}$} & \multirow{2}{*}{ Upper face } & Forehead & & & & & & & \\
\cline { 2 - 10 } & & Brows & $\mathrm{x}$ & $\mathrm{x}$ & $\mathrm{x}$ & $\mathrm{x}$ & & $\mathrm{x}$ & $\mathrm{x}$ \\
\cline { 2 - 10 } & Eye area & Eyes/eyelids & $\mathrm{x}$ & $\mathrm{x}$ & $\mathrm{x}$ & $\mathrm{x}$ & & & $\mathrm{x}$ \\
\cline { 3 - 10 } & Lower face & Nose & $\mathrm{x}$ & $\mathrm{x}$ & & $\mathrm{x}$ & & & $\mathrm{x}$ \\
\cline { 3 - 10 } & & Mouth (lips, teeth) & $\mathrm{x}$ & $\mathrm{x}$ & $\mathrm{x}$ & $\mathrm{x}$ & $\mathrm{x}$ & $\mathrm{x}$ & $\mathrm{x}$ \\
\cline { 3 - 9 } & Chin & & & & & & & \\
\hline
\end{tabular}

Table 8: Facial areas covered by somatic idioms reflecting facial displays of contempt/disgust in 7 languages

Most importantly, we can highlight that both European and East Asian languages cover both the upper and the lower face area. Again, this runs against the grain of Jack et al.'s insight that the lower facial area tends to be ignored by East Asian observers. With regard to the specific body parts covered, there is a certain variation between the seven languages. While English and German cover all body parts but the chin, Spanish does not encode the brows, and thus shows a similar pattern as Chinese, and French does not make explicit reference to the nose. The nose is also not explicated in Japanese and Korean, but it occurs with Chinese. Also Korean and Japanese somatic idioms for contempt/disgust do not point to the eye area. However, within the scope of this case study, it is impossible to explain this variation between the languages.

In summary, the inter-linguistic comparison between the 7 languages analysed in this case study reveals some interesting insights. Counter to the expectation raised by Jack et al.'s eye-movement study, East Asian somatic idioms do not ignore the lower face area. The only exception to this trend can be found with anger-related somatic idioms in Japanese and Korean, which do 
not encode the angry display of one's bare teeth. However, all the languages show a semantic overlap with somatic idioms denoting fear and surprise with reference to the eye region. This is in line with the ambiguity of this facial signal when being observed in isolation from other facial areas. Finally, there is a certain overlap between anger and contempt. Again, this ambiguity is inherent to expressions that refer to the eye region. All European languages, apart from French, further keep contempt/disgust displays separate from anger displays by explicitly pointing to the wrinkled nose. This feature is less prominent in East Asian languages, which however use alternative images to point to the distorted image of the lower face of a person experiencing disgust. Most strikingly, Korean has the expression 똥씹은 표정 ('make a face as if one had to eat excrements'), which renders this distinct facial expression by means of a highly explicit comparison. In general, the results of the inter-linguistic comparison thus generally align with the insights that we could draw from Case Study A.

\section{$7 \quad$ Conclusion}

In this paper a contrastive phraseological perspective was adopted to shed light on a psychological controversy centred about the universality vs. culture-specificity of facial expressions of emotions. While the traditional model - the Facial Action Coding System (FACS) developed by Ekman and Friesen $(1975,1978)$ - assumes a universal set of six basic or primary emotions for which facial expressions are universally recognized and displayed across cultures, Jack et al.'s (2009) eye-movement experiments speak for a cultural-relativist position. They show that East Asians adopt a culture-specific decoding strategy that concentrates their perceptual focus more on the eye region, while the lower face area is inspected to a lesser degree. Due to this culture-specific perceptual strategy, they tend to "confuse" fear with surprise and anger with disgust as the facial actions in the eyes for these emotional displays are strikingly similar and therefore potentially ambiguous.

On a methodological level, my case studies have implemented heuristic links between contrastive phraseology and construction grammar in an inner-linguistic and inter-linguistic comparison of the formal and semantic poles of somatic idioms. This methodological alignment between phraseology and construction grammar proved to be an effective tool to gain insight into the given object of analysis. The results of my two case studies have shown that somatic idioms represent the facial actions in the three facial areas, as described in the FACS, with a decent degree of accuracy. In general, all facial dimensions are encoded in all seven languages analysed. The only exception to this trend was the avoidance of encoding the mouth region (the display of the bare teeth) in Japanese and Korean idioms for anger. Of course, social display rules may have motivated this gap. Nevertheless, when looking at the more global picture, I could not observe a striking Whorfian effect, or the strong impact of culture-specific encoding/decoding rules with regard to the linguistic representation of facial expressions of emotions by somatic idioms. This general trend would be in favour of a universalist position and go against a strong cultural-relativist view.

At a closer look, however, one can observe that these facial areas are encoded opportunistically rather than very systematically in the somatic idioms from the different languages. In other words, while there is a very decent match between the representations of facial actions by the somatic idioms for some emotions, for other emotions this representation is fairly scant. For

ISSN 1615-3014 
instance, in English, as well as the six other languages inspected, the facial actions associated with surprise expressions are decently covered by the respective somatic idioms. These surprise idioms thus provide indirect linguistic evidence for the appropriateness of Ekman and Friesen's FACS. By contrast, the facial actions described for fear are not well represented by somatic idioms in any of the analysed languages. In the respective phrasal lexicons fear tends to be encoded by behaviours other than facial expressions.

Moreover, some somatic idioms that describe facial actions in the eye area are not semantically distinctive between surprise and fear as well as anger and contempt. For instance, with eyes wide open (or equivalent expressions in other languages) is semantically vague between surprise and fear and can only be disambiguated in actual usage contexts. This linguistic evidence ties in with Jack et al.'s observation that the concentration on the eye region for these emotions leads to categorization problems. However, counter to their results, this imprecise match between the senses of somatic idioms and the assumed set of basic emotions works across the seven languages rather than applies to the East Asian languages alone. In other words, there may be a more universal trend to "confuse" the facial displays of these emotions. In other words, the relationship between facial expressions and the conceptual space of emotion may not be as neat as assumed in the traditional theory. We may thus speculate that the facial expressions of some emotions may be universally ambiguous as would be suggested by the semantic mapping of some somatic idioms. This would speak for a model of emotional signalling that assumes that facial expressions alone cannot clearly communicate emotional meanings but that they often need to be combined with other emotional cues as well as contextual information (cf. Matsumoto 2012; Planalp 1998). In the light of this multimodal view of emotional display, the underlying assumption of a universal set of six basic emotions and a distinct set of corresponding facial displays that was taken as a premise in both Ekman and Friesen's and Jack et al.'s study must be questioned based on the linguistic evidence examined here. In future studies more multi-modal approaches to analysing expressions and interpretations of emotions cross-culturally would therefore be desirable in order to clarify the nature of the conceptual space of emotionality and how this space is mapped by verbal constructions as well as non-verbal signals.

Finally, several somatic idioms for facial expressions of emotions directly reflect social/cultural concepts of emotional behaviour and understanding. On the one hand, they encode display rules (e. g., to keep a stiff upper lip and to keep a straight face for 'courage' in English). On the other hand, many somatic idioms blend literal descriptions of facial displays with culture-specific metaphorical conceptualizations of emotions (e. g., to look daggers at someone). This linguistic evidence suggests that observers of facial expressions of emotion do not, and maybe cannot, draw a clear line between automatic and spontaneous facial expressions and cultural conceptualizations and interpretations of the underlying feeling states. As human beings live in socioculturally constructed worlds of experience, the neat distinction between the biological and socio-cultural substrates of their behaviours is of no practical importance to them. As reflected by somatic idioms, they rather attempt to understand the socio-emotional semiotics that surrounds them in opportunistic and culturally meaningful ways. Consequently, this should also be reflected by the heterogeneous conceptual spaces that they associate with emotions.

It goes without saying that further and more elaborate research is needed to gain a deeper understanding of the relationship between non-verbal emotional cues and linguistic constructions. This paper has attempted to provide a preliminary step in this direction from the combined 
perspective of phraseology and construction grammar. Future studies along these lines would certainly profit from systematic corpus studies on the actual use and the frequency of the somatic idioms discussed here in order to find out how and how often different somatic idioms are actually employed to describe emotional states. An interesting corpus-based case study on German somatisms that contain the constituent Finger and their potential grounding in embodied meaning has already been proposed by Ziem and Staffeldt (2011). Corresponding corpus evidence could be further combined with experiments to see how informants from different languages match idiomatic expressions to facial displays of emotion and whether there exist cross-cultural differences in doing so.

\section{References}

Bavelas, Janet et al. (1988): "Form and function in motor mimicry. Topographic evidence that the primary function is communicative". Human Communication Research 14/3: 275-299.

Burger, Harald (2007): Phraseologie. Eine Einführung am Beispiel des Deutschen. Berlin: Schmidt. (= Grundlagen der Germanistik 36).

Collins, Cobuild (1995): Dictionary of Idioms. London: Collins.

Croft, William (2001): Radical Construction Grammar: Syntactic Theory in Typological Perspective. Oxford: Oxford University Press.

Croft, William/Cruse, Alan (2004): Cognitive Linguistics. Cambridge: Cambridge University Press.

Darwin, Charles (1872): The Expression of Emotions in Man and Animals. London: Watts.

Damasio, Antonio (1994): Descartes' Error. Emotion, Reason, and the Human Brain. London: Penguin.

Damasio, Antonio (2003): Looking for Spinoza. Joy, Sorrow, and the Feeling Brain. Orlando etc.: Harcourt.

Dobrovol'skji, Dmitrij (1995): Kognitive Aspekte der Idiom Semantik. Studien zum Thesaurus deutscher Idiome. Tübingen: Narr.

Dobrovol'skij, Dmitrij/Piirainen, Elisabeth (2009): Zur Theorie der Phraseologie. Kognitive und kulturelle Aspekte. Tübingen: Stauffenburg. (= Stauffenburg Linguistik 49).

Eibl-Eibesfeldt, Irenäus (1970): Ethology. The Biology of Behavior. New York: Holt, Rinehart \& Winston.

Ekman, Paul (1973): Darwin and Facial Expression. New York: Academic Press.

Ekman, Paul (1992a): "An argument for basic emotions". Cognition and Emotion 6: 169-200.

Ekman, Paul (1992b): “Are there basic emotions?”. Psychological Review 99/3: 550-553.

Ekman, Paul (1993): "Facial expression and emotion". American Psychologist 48/4: 376-379.

Ekman, Paul (2003): Emotions Revealed. Recognizing Faces, Feelings, and their Triggers to Improve Communication and Emotional Life. New York: Times Book.

Ekman, Paul/Friesen, Wallace (1975): Unmasking the Face. A Guide to Recognizing Emotions from Facial Expressions. Englewood Cliffs: Prentice Hall.

Ekman, Paul/Friesen, Wallace (1978): Facial Action Coding System. A Technique for the Measurement of Facial Movement. Palo Alto: Consulting Psychologists Press.

Ekman, Paul/Sorenson, Richard/Friesen, Wallace (1969): "Pan-cultural elements in facial displays of emotion". Science 164: 86-88. 
Fiehler, Reinhard (2002): "How to do emotions with words: Emotionality in conversations". In: Fussell, Susan (ed.): The Verbal Communication of Emotions: Interdisciplinary Perspectives. Mahwah, Lawrence Erlbaum: 79-106.

Foolen, Ad (2012): “The relevance of emotion for language and linguistics". In: Foolen, Ad et al (eds.): Moving Ourselves, Moving Others. Motion \& Emotion in Intersubjectivity, Consciousness and Language. Amsterdam, John Benjamins: 349-369.

Goldberg, Adele (1995): Constructions. A Construction Grammar Approach to Argument Structure. Chicago: Chicago University Press.

Goldberg, Adele (2006): Constructions at Work. The Nature of Generalization in Language. Oxford: Oxford University Press.

Griffiths, Paul (1997): What Emotions Really Are. The Problem of Psychological Categories. Chicago/London: University of Chicago Press.

Harkins, Jean/Wierzbicka, Anna (2001): Emotions in Crosslinguistic Perspective. Berlin/New York: Mouton de Gruyter.

Harré, Rom (ed.) (1986): The Social Construction of the Emotions. London: Oxford University Press.

Heelas, Paul (1996): "Emotion talk across cultures". In: Harré, Rom/Parrot, Gerrod (eds.): The Emotions. London, Sage: 171-199.

Hochschild, Arlie (1983): The Managed Heart: Commercialization of Human Feeling. University of California Press: Berkeley.

Izard, Carroll (1971): The Face of Emotion. New York: Appleton-Century-Crofts.

Jack, Rachael et al (2009): "Cultural confusions show that facial expressions are not universal". Current Biology 19: 1543-1548.

James, William (1884): “What is an emotion?”. Mind 9/34: 188-205.

Kövecses, Zoltan (2002): "Emotion concepts: Social constructionism and cognitive linguistics". In Fussell, Susan (ed.), The Verbal Communication of Emotions. Interdisciplinary Perspectives. Mahwah, Lawrence Erlbaum: 109-124.

Lakoff, George (1987): Women, Fire, and Dangerous Things. What Categories Reveal About the Mind. Chicago: University of Chicago Press.

Langlotz, Andreas (2006): Idiomatic Creativity - A Cognitive-Linguistic Model of Idiom-Representation and Idiom-Variation in English. Amsterdam \& Philadelphia: John Benjamins. (= Human Cognitive Processing 17).

Matsumoto, David/Hwang, Hyi Sung/Yamada, Hiroshi (2012): "Cultural differences in the relative contributions of face and context to judgments of emotion". Journal of Cross-Cultural Psychology 43/2: 198-218.

Micheli, Raphaël (2008): «L'analyse argumentative en diachronie: le pathos dans les débats parlementaires sur l'abolition de la peine de mort». Argumentation et Analyse Du Discours 1 : $1-21$.

Michel, Caroline/Caldara, Roberto/Rossion, Bruno (2006): "Same-race faces are perceived more holistically than other-race faces". Visual Cognition 14(1): 55-73.

Motley, Michael/Camden, Carl (1988): "Facial expression of emotion: A comparison of posed versus spontaneous expressions in an interpersonal-communication setting”. Western Journal of Speech Communication 52: 1-22.

Nunberg, Geoffrey/Sag, Ivan/Wasow, Thomas (1994): “Idioms". Language 70(3): 491-538. 
Ochs, Elinor/Schieffelin, Bambi (1989): "Language has a heart". Text 9(1), special issue: The Pragmatics of Affect: 7-25.

Pavlenko, Aneta (2002): "Emotions and the body in Russian and English". Pragmatics and Cognition 10(1/2): 207-241.

Planalp, Sally (1998): "Communicating emotion in everyday life: cues, channels, and processes". In: Andersen Peter/Guerrero, Laura (eds.): Handbook of Communication and Emotion: Research, Theory, Applications, and Contexts. San Diego, Academic Press: 29-48.

Planalp, Sally (1999): Communicating Emotion: Social, Moral, and Cultural Processes. Cambridge: Cambridge University Press.

Plutchik, Robert (1962): The Emotions. Facts, Theories, and a New Model. New York: Random House.

Plutchik, Robert (1980): Emotion. A Psychoevolutionary Synthesis. New York: Harper \& Row.

Plutchik, Robert (2003): Emotions and Life. Perspectives from Psychology, Biology, and Evolution. Washington: American Psychological Association.

Roget's Thesaurus online. www.thesaurus.com [20.12.2017].

Russell, James A. (1994): "Is there universal recognition of emotion from facial expression? A review of cross-cultural studies". Psychological Bulletin 115: 102-141.

Schwarz-Friesel, Monika (2007): Sprache und Emotion. Tübingen. Francke.

Wierzbicka, Anna (1995): "Everyday conceptions of emotion. A semantic perspective". In: Russell, James et al (eds.): Everyday Conceptions of Emotion. Dordrecht, Kluwer: 19-47.

Wilce, James M. (2009): Language and Emotion. Cambridge: Cambridge University Press.

Wikipedia. "List of emoticons". http://en.wikipedia.org/wiki/List_of_emoticons [07.06.2013].

Ziem, Alexander/Staffeldt, Sven (2011): "Compositional and embodied meanings of somatisms. A corpus-based approach to phraseologisms”. In: Schönefeld, Doris (ed.): Converging Evidence. Methodological and Theoretical Issues for Linguistic Research. Amsterdam/Philadelphia, John Benjamins: 195-219. 
Appendix - List of somatic idioms analysed

\section{Japanese idioms}

\begin{tabular}{|l|l|l|}
\hline Idiom & English gloss & Meaning \\
\hline 眉間にしわを寄せる & bend/knot one's brows & be angry \\
\hline 目をぱちくりする & blink many times & cause surprise \\
\hline にらむ & look daggers at someone & look angrily \\
\hline 眉をひそめる & $\begin{array}{l}\text { wrinkle one's brow in displeasure } \\
\text { or anger, scowl, glower }\end{array}$ & be annoyed/show contempt \\
\hline 鼻で笑う & sneer, smile ironically & show contempt \\
\hline アッと驚く & open one's mouth and eyes & be very surprised \\
\hline 目を丸くする & open one's eye wide & be very surprised \\
\hline 口をゆがめる & distort the mouth & show disgust/contempt \\
\hline 目を吊り上げる & raise the outer corner of the eyes & be very angry \\
\hline
\end{tabular}

\section{Chinese idioms}

\begin{tabular}{|l|l|l|}
\hline Idiom & English gloss & Meaning \\
\hline 引人側目 & raise eyebrows & cause surprise \\
\hline 憤怒的目光盯著別人 & stare someone with angry eyes & look angrily \\
\hline $\begin{array}{l}\text { 白鴿眼/眼睛長在額頭 } \\
\text { 上 }\end{array}$ & $\begin{array}{l}\text { pigeon's eyes / eyes grows on the } \\
\text { forehead }\end{array}$ & be annoyed/show contempt \\
\hline 虽之以鼻 & to turn your nose up at someone & show contempt \\
\hline 呆若木鸡 & dumb as a wooden rooster & be very surprised \\
\hline 掉眼鏡 & drop my eyeglasses & be very surprised \\
\hline 藐嘴藐舌 & curl one's lip and tongue & show disgust/contempt \\
\hline & & show disgust/contempt \\
\hline 咬牙切齿 & bite your own teeth & be very angry \\
\hline
\end{tabular}

\section{Korean idioms}

\begin{tabular}{|l|l|l|}
\hline Idiom & English gloss & Meaning \\
\hline 눈이 휘둥그레지다 & with eyes wide open & be surprised/be shocked \\
\hline 눈알이 나오다 & eyeballs come out of the head & be very surprised \\
\hline 입이 떡 벌어지다 & with a wide open mouth & be very surprised \\
\hline 눈알이 곤두서다 & eyeballs stand out & be very angry \\
\hline 눈에 쌍심지를 켜다 & a candlewick ignites in the eyes & be very angry \\
\hline 눈에 천불이 나다 & fire comes out of the eyes & be furious \\
\hline 미간을 찌푸리다 & to frown between the eyes & show disgust/contempt \\
\hline $\begin{array}{l}\text { 똥씹은 표정 } \\
\text { make a face as if one had to eat } \\
\text { excrements }\end{array}$ & show disgust/contempt \\
\hline 입을 씰룩거리다 & the mouth shakes & show disgust/contempt \\
\hline
\end{tabular}

\section{German idioms}

\begin{tabular}{|l|l|l|}
\hline Idiom & English gloss & Meaning \\
\hline $\begin{array}{l}\text { die Augen weit aufreis- } \\
\text { sen }\end{array}$ & opens one's eyes very widely & be surprised/be shocked \\
\hline grosse Augen machen & make big eyes & be very surprised \\
\hline $\begin{array}{l}\text { jmdm. fallen (fast) die } \\
\text { Augen aus dem Kopf }\end{array}$ & $\begin{array}{l}\text { somebody's eyes fall out of the } \\
\text { head }\end{array}$ & be very surprised \\
\hline
\end{tabular}




\begin{tabular}{|l|l|l|}
\hline $\begin{array}{l}\text { die Augenbrauen hoch- } \\
\text { ziehen }\end{array}$ & raise one's eyebrows & be very surprised \\
\hline $\begin{array}{l}\text { mit offenem Mund da- } \\
\text { stehen }\end{array}$ & stand with a wide open mouth & be very surprised \\
\hline $\begin{array}{l}\text { jmdm. fällt die Kinnlade } \\
\text { runter }\end{array}$ & someone's chin drops down & be speechless with surprise \\
\hline die Stirn runzeln & to frown & be angry \\
\hline $\begin{array}{l}\text { mit zusammengezoge- } \\
\text { nen Augenbrauen }\end{array}$ & with eyebrows pulled together & scornful \\
\hline $\begin{array}{l}\text { mit stechenden Augen } \\
\text { mit stechendem Blick }\end{array}$ & with stinging eyes & be very angry \\
\hline Zähne zeigen & to show one's teeth & be very angry \\
\hline $\begin{array}{l}\text { mit zusammengezoge- } \\
\text { nen Augenbrauen }\end{array}$ & with eyebrows pulled together & be very angry \\
\hline $\begin{array}{l}\text { die Augen verdre- } \\
\text { hen/rollen }\end{array}$ & to roll one's eyes & be full of contempt \\
\hline die Nase rümpfen & to wrinkle the nose & show disgust/contempt \\
\hline eine Schnute ziehen & to make a wry mouth & show disgust/contempt \\
\hline $\begin{array}{l}\text { einen schiefen Mund } \\
\text { machen }\end{array}$ & to make a wry mouth & show disgust/contempt \\
\hline
\end{tabular}

\section{French idioms}

\begin{tabular}{|l|l|l|}
\hline Idiom & English gloss & Meaning \\
\hline ouvrir des yeux ronds & open round eyes & be surprised/be shocked \\
\hline $\begin{array}{l}\text { ouvrir des grands yeux } \\
\text { lever hausser les sour- } \\
\text { cils }\end{array}$ & make big eyes & be very surprised \\
\hline $\begin{array}{l}\text { regarder qn. bouche } \\
\text { bée }\end{array}$ & $\begin{array}{l}\text { look at someone with a wide open } \\
\text { mouth }\end{array}$ & be very surprised \\
\hline rester bouche bée & keep one's mouth wide open & be very surprised \\
\hline plisser le front & to frown & be angry \\
\hline froncer les sourcils & pull one's eyebrows together & scornful \\
\hline fusiller du regard & to shoot with one's gaze & be very angry \\
\hline montrer ses dents & to show one's teeth & be very angry \\
\hline rouler les yeux & to roll one's eyes & be full of contempt \\
\hline faire une moue & to make a wry mouth & show disgust/contempt \\
\hline
\end{tabular}

\section{Spanish idioms}

\begin{tabular}{|l|l|l|}
\hline Idiom & English gloss & Meaning \\
\hline $\begin{array}{l}\text { abrir unos ojos como } \\
\text { platos }\end{array}$ & opens one's eyes like plates & be surprised/be shocked \\
\hline abrir tanto ojo & make big eyes & be very surprised \\
\hline arquear las cejas & raise one's eyebrows & be very surprised \\
\hline con la boca abierta & with an open mouth & be very surprised \\
\hline fruncir el ceño & to frown & be angry/show contempt \\
\hline con ojos agudos & with stinging eyes & be very angry \\
\hline enseñar los colmillos & to show one's teeth & be very angry \\
\hline $\begin{array}{l}\text { poner los ojos en } \\
\text { blanco }\end{array}$ & to put the eyes into white & be full of contempt \\
\hline arrugar la nariz & to wrinkle the nose & show disgust/contempt \\
\hline poner morros & to make a wry mouth & show disgust/contempt \\
\hline
\end{tabular}




\section{English idioms}

\begin{tabular}{|l|l|}
\hline Idiom & Meaning \\
\hline raise eyebrows & cause surprise \\
\hline $\begin{array}{l}\text { open-mouthed } \\
\text { with gaping mouth }\end{array}$ & be very surprised \\
\hline your jaw drops & be very surprised \\
\hline bend/knit one's brows & be angry \\
\hline $\begin{array}{l}\text { look daggers at some- } \\
\text { one }\end{array}$ & look angrily \\
\hline show/gnash your teeth & be very angry \\
\hline $\begin{array}{l}\text { turn up one's eyes, with } \\
\text { upturned eyes }\end{array}$ & be annoyed/show contempt \\
\hline $\begin{array}{l}\text { to turn your nose up at } \\
\text { someone/something }\end{array}$ & show contempt \\
\hline curl one's lip & show disgust/contempt \\
\hline make a wry mouth & show disgust/contempt \\
\hline
\end{tabular}

